\title{
Intrinsic Adherence to Law: Physical versus Intellectual Property
}

\section{Working Paper}

\section{Author(s):}

Bechtold, Stefan (1D; Gertsch, Gabriel; Schonger, Martin (i)

Publication date:

2019-10

Permanent link:

https://doi.org/10.3929/ethz-b-000376210

Rights / license:

In Copyright - Non-Commercial Use Permitted

Originally published in:

Center for Law \& Economics Working Paper Series 01/2019 


\section{GHzürich}

\section{Center for Law \& Economics Working Paper Series}

Number 01/2019

Intrinsic Adherence to Law:

Physical versus Intellectual Property

Stefan Bechtold

Gabriel Gertsch

Martin Schonger 


\title{
Intrinsic Adherence to Law:
}

\section{Physical versus Intellectual Property}

\author{
Stefan Bechtold, Gabriel Gertsch and Martin Schonger*
}

October 2019

\begin{abstract}
Infringement of intellectual property seems to be much more common than infringement of physical property. Intellectual property rights protect non-rival goods that are non-rival in consumption, while physical property rights protect rival goods. Non-rivalry implies that the owner suffers no direct harm from infringement. This could explain lower respect for property rights in non-rival goods. To test this hypothesis, we isolate the dimension of rivalry in an experiment. We develop a theft game that offers plausible deniability and minimizes experimenter demand for theft. We find no evidence, neither in behavior nor in social norms, that participants' respect for non-rival goods is lower than for rival goods. To determine whether this indicates absence of evidence or evidence of absence, we use Bayesian factor analysis. The analysis demonstrates evidence of absence. These findings suggest that widespread infringement of intellectual property cannot be explained by its non-rival nature.
\end{abstract}

\footnotetext{
${ }^{*}$ Center for Law \& Economics, ETH Zurich, Switzerland. The authors can be reached at sbechtold@ethz.ch, gabriel.gertsch@gess.ethz.ch, and mschonger@ethz.ch. JEL classifications: C91, K11, K14, O34. Keywords: property rights, intellectual property, non-rival goods, stealing aversion. For helpful comments and discussions, we thank conference participants at ILEA, Cardozo Empirical Methods in IP Roundtable, Munich Summer Institute, ETH Patents! Workshop, EPIP, EALE, and seminar participants at ETH Zurich, University of Chicago Law School, and ZHAW Winterthur. Scott Reiser provided excellent research assistance. We gratefully acknowledge funding by the Swiss National Science Foundation.
} 


\section{Introduction}

Growth depends, in the words of Robert Solow (1987), "entirely on the rate of technological progress." Technology and knowledge are non-rival and non-excludable, as are many other goods essential to human welfare, such as music or literature. Absent legal protection, freeriders can consume such goods without compensating innovators and creators. This may lead to underprovision due to a lack of incentives for creation (Landes and Posner 2003, 1216). Legislators have instituted intellectual property rights to solve this problem. However, infringement of all types of intellectual property - including patents, copyrights, trademarks, designs and trade secrets - is commonplace, by actors ranging from consumers to senior employees and companies themselves.

Carnegie Mellon University, for example, sued chip manufacturer Marvell in 2009 for using two hard disk technology patents in billions of chips without authorization. Marvell later agreed to pay Carnegie Mellon University $\$ 750$ million to settle the lawsuit (Day and Udick 2019, 138-140). Smartphone manufacturers have been suing and counter-suing each other in legal fora around the globe, demanding aggressive injunctive relief and multi-billion dollar damage awards for alleged utility and design patent infringements (Graham and Vishnubhakat 2013; Paik and Zhu 2016). In 2016, Anthony Levandowski, a senior employee of Alphabet's selfdriving car unit Waymo, quit his job to found his own company, later acquired by Uber. Upon leaving Waymo, Levandowski copied, without authorization, about 14,000 digital files on selfdriving car technology. A later trade secret lawsuit settled for $\$ 245$ million. ${ }^{1}$ Infringement of intellectual property is also common among ordinary citizens. For instance, $51 \%$ of European adults (and $72 \%$ of minors) infringe copyright through illegal downloading or streaming. ${ }^{2}$

Tyler (1997), Manesh (2006, 76), Rhode (2019, 93), and the examples above suggest that intellectual property rights are more frequently and more severely infringed upon than rights in physical property. According to survey evidence (Poltrack 2013), $78 \%$ of Americans view

\footnotetext{
${ }^{1}$ See Complaint, Waymo LLC v. Uber Technologies, Inc., et al., 2017 WL 726994 (N.D. Cal. 2017).

${ }^{2}$ Figures refer to the European Union in 2014 (van der Ende et al. 2014).
} 
infringement of physical property as a serious offense but merely $40 \%$ hold the same view when intellectual property is concerned. Similarly, many people would never buy stolen goods, such as a smartphone or handbag. At the same time, however, most people have no qualms about buying a smartphone whose production violates third-party patent rights ${ }^{3}$ or a fake handbag, violating trademark and design rights (Barnett 2005). This forms part of a growing body of evidence documenting that people view infringement of intellectual property as less morally condemnable (Lysonski and Durvasula 2008; Wingrove et al. 2011; Krawczyk et al. 2015; Hergueux and Jemielniak 2019). Other explanations for widespread infringement of intellectual property have been proposed. Mandel et al. (2015, 918, 951) and Fast et al. (2017) argue that people fail to comply with intellectual property laws because they misconceive the scope and goals of the latter. Another explanation is deterrence theory, which holds that adherence to the law depends on the expected costs and benefits of a crime (Becker 1968). That is, the probability and severity of punishment for intellectual property infringement may be insufficient (see Buccafusco and Masur 2013). Interestingly, Becker (1968, 10) already points out that the utility from committing an offense is not only a function of the monetary but also of the psychic costs of the offense. In this paper, we investigate the last explanation, the hypothesis that the psychic costs of infringing intellectual property versus physical property differ.

One reason to believe that psychic costs may differ is that physical property is typically a rival good, while intellectual property is typically a non-rival good. Hence, infringement or theft of a physical good harms the owner, since he can no longer consume the good. By contrast, infringement of intellectual property does not diminish the owner's consumption opportunities. ${ }^{4}$ Noting this difference, people may view infringement of physical property

\footnotetext{
${ }^{3}$ Estimates for standard-essential patent royalty fees per smartphone range from $3.3 \%$ to more than $30 \%$ of the smartphone's selling price (see Galetovic et al. 2018, 266, 271 (3.3\%); Sidak 2016, 703, 719 (4-5\%); Dedrick and Kraemer 2017, 14, 17, and Mallinson 2015 (5\%); World Intellectual Property Organization 2017, 99 (11-12\%); Fairphone 2015 (12\%); Armstrong et al. 2014, 3, 68 (30\%); for an overview, see Contreras 2019). Note that the value of all intellectual property rights on a smartphone is likely to be even higher if licenses for non-essential patents and intellectual property rights other than patents are also included.

${ }^{4}$ To be sure, the owner would be better off if the infringer paid for using the good. Compared to non-
} 
rights as illegitimate due to the harm caused to the owner, while viewing infringement of intellectual property rights as legitimate since the owner is not harmed. In addition, people may fail to see that infringement of intellectual property rights may do great harm by reducing the incentives for creation.

Thus, adherence to property rights may be partially driven by the intrinsic motivation of the property's user, which, in turn, may depend on the nature of the good protected by the property right. Identifying the causal effect of the rival versus non-rival nature of a good on intrinsic adherence to property rights protecting that good is challenging. Observational data on theft (Buonanno et al. 2009) and intellectual property infringement (Goel and Nelson 2009; Athey and Stern 2015) suffer from detection bias. While surveys have explored how deterrence affects copyright infringement (LaRose et al. 2005; Al-Rafee and Cronan 2006; LaRose and Kim 2007; Li and Nergadze 2009; Liao et al. 2010; for overviews, see Williams et al. 2010; Watson et al. 2015; Fleming et al. 2017), such studies are typically subject to the limitation that they are not incentivized. Moreover, when illicit behavior is concerned, eliciting truthful answers using vignettes (for example, Green and Kugler 2010; Depoorter et al. 2011; Depoorter and Van Hiel 2015) or survey items is subject to social desirability bias.

In order to overcome these limitations, we employ an incentivized lab experiment. We design a novel game, the theft game, where one participant, the user, decides whether to steal a good from another participant, the owner. The design of the experiment gives the user plausible deniability of theft. An innovation of our theft game is that the deniability perceived by the user is higher than the true deniability. Furthermore, our experimental task allows us to vary whether the good is rival or non-rival. These two novel features of the theft game - variation of the rival versus non-rival nature of the good and plausible deniability - allow us to causally isolate the impact of (non-)rivalry on stealing. ${ }^{5}$

We conduct a lab study with 300 participants. Incentives are salient, users earn on average infringement, however, the owner is not worse off (and indeed may not even notice infringement).

${ }^{5}$ For the sake of brevity, we refer to the infringement of physical and intellectual property as "stealing" and "theft." No normative or other claims are intended by this terminology. 
more than $10 \%$ of their monthly budget net of rent. Perceived and true deniability differ in the theft game. On average, the former is $47 \%$ across all rounds and the latter $32 \%$. Round 7 is designed for maximal difference between the two, with perceived deniability at $34 \%$ and true deniability at $0 \%$. The study yields three main results: First, when users have the possibility to steal, they do so about one out of two times. Second, regarding our main hypothesis, we do not find any evidence that the fraction of participants who steal differs between the rival and non-rival treatments. Third, behavior is mirrored in social norms: We find no difference in the distribution of views on the social appropriateness of stealing. Given these surprising results, we conduct a robustness treatment to exclude that outcome-based preferences explain the findings.

The paper proceeds as follows. Section 2 first discusses previous experimental models of theft and then develops our own, the theft game. Two attractive features of the design are explained: Minimal experimenter demand and the separation of perceived and true deniability. Section 3 presents and discusses the results and investigates their robustness. Section 4 concludes.

\section{Design}

We conduct an incentivized lab experiment to study whether participants take non-rival goods more often than rival goods. In order to minimize experimenter demand for stealing, we design a novel game, the theft game. The theft game has two players, the owner and the user. First, the owner has six minutes to complete a Scrabble task. The user then has three minutes to complete the task. Midway through the three minutes, however, the owner's solution is displayed to the user. The user has to decide whether to buy or steal the owner's solution or do nothing. A shortened version of our game can be played online. ${ }^{6}$

Investigating illegitimate behavior, such as theft, in the laboratory is challenging, as it is susceptible to experimenter demand. Thus, we first discuss these challenges, and the solutions

\footnotetext{
${ }^{6}$ Available at www.lawecon.ethz.ch/ipexperiment.
} 
proposed in the previous literature (section 2.1). Building on this, we propose our theft game (section 2.2) and discuss how it implements plausible deniability (section 2.3). In section 2.4, we discuss how the game can be used for our research question, the inclination of participants to steal rival versus non-rival goods. Section 2.5 gives the procedure of the experiment.

\subsection{Theft in the Laboratory}

Recent experimental studies investigate the determinants of theft. The paradigm to study stealing in this literature is the dictator game, where the recipient instead of the dictator is allocated the initial endowment. Taking from the recipient is then interpreted as stealing. Schildberg-Hörisch and Strassmair (2012), Rizzolli and Stanca (2012), Harbaugh et al. (2013), Engel and Nagin (2015), Khadjavi (2015), Engel (2016), Khadjavi (2018), Feess et al. (2018) use this design to study deterrence, Pecenka and Kundhlande (2013) focus on racial discrimination, Falk and Fischbacher (2002) and Fleming et al. (2016) investigate social determinants of theft and Baumann and Friehe (2017) study preferences for punishment of theft.

Experimenter demand is a key concern when studying theft in the lab. Zizzo (2010) concludes that dictator games are exceptionally affected by experimenter demand. A study by de Quidt et al. (2018) measures experimenter demand effects in eleven canonical experiments and finds, using data from 19,000 participants, that the dictator game is particularly affected. When using dictator games to study stealing, experimenter demand creates two main issues, non-anonymity and legitimization. First, Levitt and List (2007) show that when participants feel their potentially illegitimate behavior is observed, they tend to behave more pro-socially. Second, an experimental design may legitimize illegitimate behavior if it is obvious to participants that behaving illegitimately is what the study is about. As Zizzo (2010) shows, realizing the purpose of an experiment inclines participants to act in line with the purpose. Participants

are explicitly asked about their stealing decision in the previous experimental literature on stealing, which may cause experimenter demand for stealing. Hoffman et al. (1994) propose 
an elegant solution to non-anonymity, a double-blind procedure. Studies using this procedure to investigate stealing include Kettner and Ceccato (2014), Kettner and Waichman (2016) and Faillo et al. (2018). Unfortunately, legitimization remains an issue.

We develop a new theft game whose design addresses the two issues arising from experimenter demand by offering two features: Plausible deniability and the seemingly incidental nature of illegitimate behavior. Participants believe that their illicit behavior cannot be observed by the experimenter and underestimate our ability to draw statistical inferences regarding behavior. In addition, the possibility of stealing arises such that it appears incidental to participants. Thus, the design does not legitimize stealing.

\subsection{Theft Game}

In the theft game, both the owner and the user can create goods by completing Scrabble tasks. The user, in whose behavior we are interested, can buy or steal a good from the owner. The owner and the user both receive the same nine letters to form words, but the permutation of letters can differ, which is pointed out to users. ${ }^{7}$ This allows us to choose separate levels of difficulty. The owner can only submit long solutions (words with eight or more letters), and his induced valuation is $v_{o}$. The user can submit both short (words with five to seven letters) and long solutions, and she can submit as many solutions as she likes. She has an induced valuation of $v_{C}$ for a long solution and $s$ for a short solution, where $s<v_{C}$. The user receives no payoff for solutions shorter than five letters. The scrambles are constructed such that there is no nine-letter solution, exactly one eight-letter solution, and several short solutions. Knowledge of the long solution inspires short solutions, particularly as the Scrabble dictionary includes plurals, declinations, and conjugations. For instance, consider the scramble YFLLOYJXU. It contains the eight-letter word JOYFULLY. Knowing the long solution, it is easy to come up with JOYFUL and FULLY.

\footnotetext{
${ }^{7}$ In each solution, each letter can only be used as many times as provided. Whether a solution is valid is decided by the official German Scrabble dictionary. Different adaptions of Scrabble have been used in Crosetto (2010), Bechtold et al. (2016), Brüggemann et al. (2016), and Brüggemann and Meub (2017).
} 
First, the owner has six minutes to complete the Scrabble task, then the user has three minutes. The user's three minutes are divided into two halves of 90 seconds each. During the first half, the user is only shown the scramble. During the second half, she is additionally shown the long solution of the owner, provided he has found it (figure 1). Recall that the long solution inspires short solutions. Therefore, the user can use it to develop her own solutions. After the three minutes, the user sees a screen where she can submit all her short solutions (prior to that, she can write them down on paper). On the subsequent screen (figure 2), she then chooses one of three mutually exclusive options regarding the long solution:

"Do nothing": User does not submit the long solution.

"Buy": User buys the solution for price $p>0$ and submits it.

Note that a user who has not found the long solution independently before it is shown to her can, nevertheless, claim she did find the solution by choosing $(C)$ Submit. Such a claim cannot be disproven. We say a user steals a solution if she has not found the long solution through own work and, nevertheless, chooses $(C)$ Submit.

In addition to the payoffs for solutions, the owner receives an endowment $\omega$. Assuming the owner has found the long solution, while the user has not found the long solution but has found $n$ short solutions, the following payoff vectors result, where the first entry corresponds to the user: For $(A)$ Do nothing $\left(n s, v_{o}+\omega\right)$; for $(B)$ Buy $\left(v_{U}+n s-p, p+\omega\right)$; and for $(C)$ Submit $\left(v_{U}+n s, \omega\right)$. To ensure that buying is a Pareto improvement, we pick parameters such that

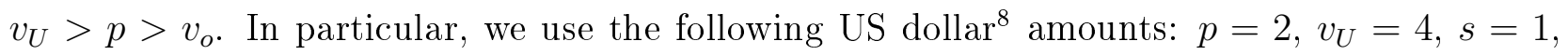
$v_{o}=1, \omega=1$.

\footnotetext{
${ }^{8}$ As the study was conducted in Switzerland, participants received Swiss francs. The Swiss franc was at parity with the US dollar at the time of the study.
} 


\section{Task $1 / 10$}

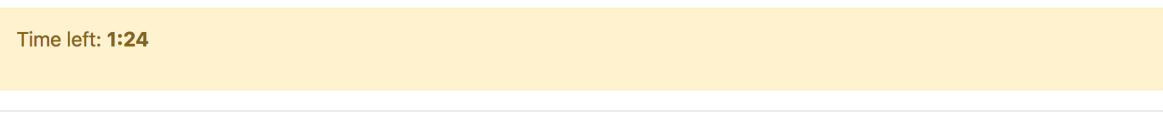

Please form valid words with 5 or more letters from these 9 letters:

\begin{tabular}{|l|l|l|l|l|l|l|l|l|}
\hline $\mathbf{L}$ & $\mathbf{L}$ & $\mathbf{O}$ & $\mathbf{U}$ & $\mathbf{J}$ & $\mathbf{F}$ & $\mathbf{X}$ & $\mathbf{Y}$ & $\mathbf{Y}$ \\
\hline
\end{tabular}

Solution of the green participant:

\begin{tabular}{l|l|l|l|l|l|l|l|}
$\mathbf{J}$ & $\mathbf{O}$ & $\mathbf{Y}$ & $\mathbf{F}$ & $\mathbf{U}$ & $\mathbf{L}$ & $\mathbf{L}$ & $\mathbf{Y}$ \\
\hline
\end{tabular}

Figure 1: Scrabble Task

The figure shows the screen of the user in the second half of her three minutes. During the first 90 seconds, only the nine-letter scramble is displayed. During the second 90 seconds, the long solution of the owner, here JOYFULLY, is displayed, provided the owner has found it. Short solutions that can be derived from JOYFULLY include JOYFUL and FULLY. To frame the experiment neutrally, the owner is referred to as the "green participant."

Note: You can enter JOYFULLY only on this page.

\begin{tabular}{|c|c|c|}
\hline \multicolumn{3}{|l|}{$\begin{array}{l}\text { You have three options regarding JOYFULLY: } \\
\text { (A) Do nothing }\end{array}$} \\
\hline \multicolumn{3}{|c|}{$\begin{array}{l}\text { If you buy and submit (B), or submit without buying (C), only you will receive money for JOYFULLY. The green participant } \\
\text { loses this solution. }\end{array}$} \\
\hline \multicolumn{3}{|c|}{$\begin{array}{l}\text { Regarding option (C): We cannot determine whether you really arrived at this solution on your own. Thus, your decision alone } \\
\text { determines your earnings and the earnings of the green participant for JOYFULLY. }\end{array}$} \\
\hline (A) Do nothing & (B) Buy and submit & (C) Submit without buying \\
\hline You: CHF 0. & $\begin{array}{l}\text { You: CHF } 4 \text { for JOYFULLY minus the } \\
\text { price of CHF 2, hence CHF } 2 .\end{array}$ & You: CHF $\mathbf{4}$ for JOYFULLY. \\
\hline $\begin{array}{l}\text { Green participant: CHF } 1 \text { for } \\
\text { JOYFULLY plus CHF } 1 \text { round wage, } \\
\text { hence CHF } 2 .\end{array}$ & $\begin{array}{l}\text { Green participant: CHF } 0 \text { for } \\
\text { JOYFULLY, the price of CHF } 2 \text { plus } \\
\text { CHF } 1 \text { round wage, hence CHF } 3 .\end{array}$ & $\begin{array}{l}\text { Green participant: CHF } 0 \text { for } \\
\text { JOYFULLY plus CHF } 1 \text { round wage, } \\
\text { hence CHF } 1 .\end{array}$ \\
\hline \multicolumn{3}{|c|}{$\begin{array}{l}\text { Please note: If you have entered other solutions on the previous screen, you receive additional money for those. The green } \\
\text { participant cannot enter other solutions. }\end{array}$} \\
\hline \multicolumn{3}{|c|}{$\begin{array}{c}\text { If you choose }(\mathrm{C}) \text {, you submit JOYFULLY without } \\
\text { buying this solution. The green participant loses } \\
\text { this solution and does not receive the price from } \\
\text { you. }\end{array}$} \\
\hline
\end{tabular}

Figure 2: Do Nothing, Buy, or Submit? (Rival Treatment)

The figure shows the screen of the user in the rival treatment facing the decision between $(A)$ Do nothing, $(B)$ Buy, or $(C)$ Submit. In the example shown, the owner has found the long solution JOYFULLY, and the user is selecting $(C)$ Submit. After users have selected $(A),(B)$, or $(C)$, the red text reminds them of the consequences for the owner. If the user had chosen $(A)$ Do nothing, the red confirmation text would be "If you choose $(A)$, you neither buy JOYFULLY nor submit this solution without buying it," if she had chosen $(B)$ Buy, the red text would be "If you choose $(B)$ you buy JOYFULLY and submit this solution. The green participant loses this solution, but receives the price from you." See figure A.1 in the appendix for the non-rival treatment. 


\subsection{Perceived and True Deniability}

A challenge for lab studies on illicit behavior is that participants may feel that they are observed by the experimenter, which may contaminate the results. This challenge can be addressed by giving participants plausible deniability of the illicit action. For example, in a seminal study on lying, Fischbacher and Föllmi-Heusi (2013) let participants privately roll a six-sided die and pay them according to the outcome reported. Thus, even very advantageous outcomes can be explained by participants as luck. ${ }^{9}$ While lying cannot be observed by the experimenter on an individual level, it can be inferred statistically on an aggregate level. Fischbacher and Föllmi-Heusi (2013) pay the highest reward for rolling a 5. The probability of rolling a 5 is $1 / 6$, which we call the true deniability. At the same time, participants' belief about this probability is also $1 / 6$, which we call the perceived deniability. Our theft game offers plausible deniability in the same vein. If the user chooses $(C)$ Submit, the experimenter cannot know with certainty whether the user is stealing, but can make a statistical inference. However, our design improves the statistical inference vastly, and allows near-certain inferences at the individual level: In the theft game, true deniability is lower than perceived deniability. This wedge arises because participants have to form beliefs about how hard it is to complete a Scrabble task within 90 seconds, and, on average, they underestimate the difficulty.

The difference between perceived and true deniability varies from round to round. In some rounds, they are about equal. In other rounds, however, it is nearly impossible for users to find the long solution within 90 seconds, but they still believe it is doable. To estimate the perceived and true deniability parameters for each round, we conduct four auxiliary sessions with 138 participants. ${ }^{10}$ Participants receive exactly the same scrambles and permutations as

\footnotetext{
${ }^{9}$ Plausible deniability is further increased in the adaptation of Kajackaite and Gneezy (2017), where participants are asked to think of a number and receive money if they report having rolled it. Gravert (2013) adapts the design of Fischbacher and Föllmi-Heusi (2013) to a study where participants can steal from the experimenter rather than from other participants.

${ }^{10}$ The sessions took place in the ETH Decision Sciences Laboratory in 2018 and 2019. Participants were recruited from the same subject pool as in the main sessions. In the first session $(N=35)$, participants completed the Scrabble tasks used in the main sessions. In the three remaining sessions $(N=103)$, participants also completed those tasks, but we additionally elicited beliefs about the fraction of participants who could
} 


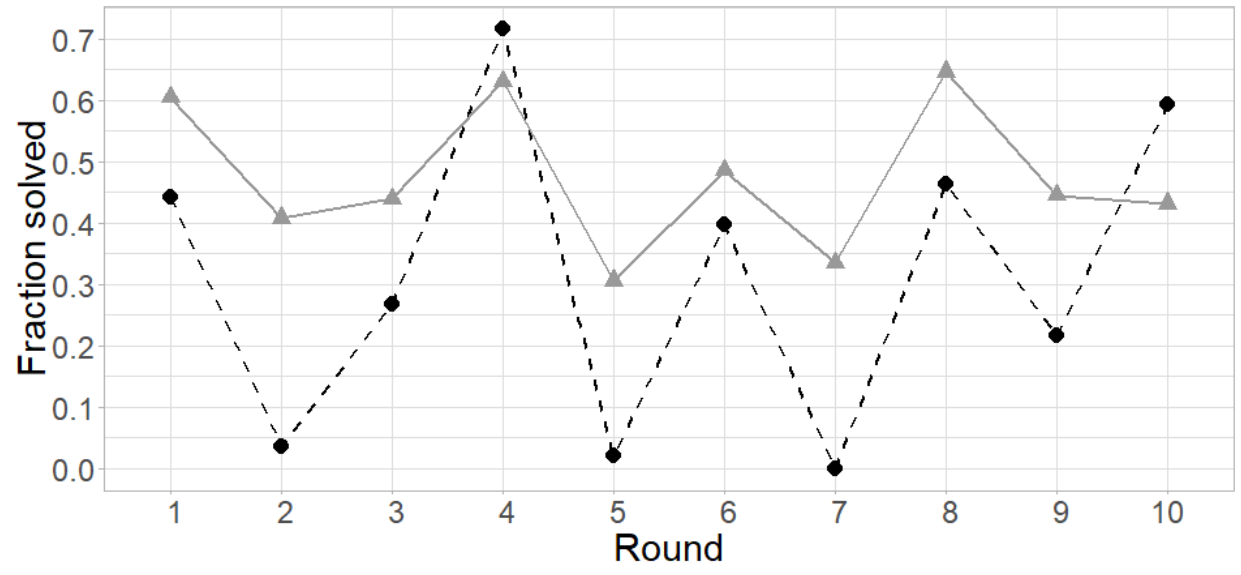

Fraction solved $\leq 90$ seconds (true deniability)

- Belief about fraction solved $\leq 90$ seconds (perceived deniability)

Figure 3: Perceived and True Deniability

True deniability is defined as the fraction of participants who found the long solution within 90 seconds $(N=138)$. Perceived deniability is defined as participants' belief about true deniability $(N=103)$. The data is from four separate, auxiliary sessions (footnote 10).

users in the main sessions and are asked to solve within 90 seconds. They then state their belief about the percentage of participants who could solve the scramble within that time limit. Both parts of the study are incentivized. Figure 3 illustrates the results. Beliefs about task difficulty track actual difficulty to some extent. Across all rounds, the correlation between actual and believed average percentage solved is 0.79 . However, participants systematically underestimate the difficulty of the Scrabble tasks. In other words, perceived deniability lies above true deniability. The best example is round 7 , where the scramble is so difficult that none of the 138 participants is able to solve it, yet, on average, participants believe that $34 \%$ of participants are able to do so.

We discuss plausible deniability with the example of round 7. No user is able to find the long solution in that round. Nevertheless, if a user chooses $(C)$ Submit, she believes it plausible to claim that she did find the solution on her own as, on average, she believes about a third of

find the long solution within 90 seconds. Both parts were incentivized, where the first session served as the ground truth on which incentives for the elicitation of beliefs were based. The session duration was 70 minutes, average earnings were USD 34.70. The sequence of instructions and screens used are documented in the online supplement to the auxiliary sessions. 
users do find it. That is, while the user perceives deniability of theft to be $34 \%$, the auxiliary sessions show that true deniability is $0 \%$. Thus, while the user perceives theft to be plausibly deniable, the experimenter knows it is almost certain that she stole the solution. Hence, our design not only provides high perceived deniability to participants (34\% in round 7 versus about $17 \%$ in Fischbacher and Föllmi-Heusi 2013) but also allows inferring stealing behavior, for round 7 with virtual certainty, without deceiving participants.

This design makes plausible deniability seemingly a natural consequence of the Scrabble task rather than a deliberate choice by the experimenter. This is an improvement on the paradigm of using dictator games to study stealing in the lab, even when a double-blind procedure is implemented. The owner's solution is displayed to the user seemingly for the reason that it inspires short solutions. In addition, option $(C)$ Submit appears to be designed for users who found the solution on their own. At the same time, users can steal without fearing being judged, or even observed, by the experimenter. This ensures that participants do not perceive a sanction that is not intended by the experimenter, while also reducing experimenter demand for illicit behavior.

\subsection{Theft of a Non-rival Good}

The treatment varies from the baseline in that the good is non-rival (corresponding to intellectual property) rather than rival (corresponding to physical property) in consumption. The rival or non-rival nature of the good is implemented by varying the induced valuation of the owner for his solution. If the good is non-rival, the owner can consume the good even if the user chooses $(B)$ Buy or $(C)$ Submit, while he cannot if the good is rival. Thus, if a user chooses $(C)$ Submit, this worsens the outcome for the owner if the good is rival, but not if it is

non-rival. Assuming the owner has found the long solution and the user has not found the long solution but has found $n$ short solutions, the following payoff vectors result in the non-rival treatment, where the first entry corresponds to the user: For $(A)$ Do nothing $\left(n s, v_{o}+\omega\right)$; for 
Table 1: Payoffs as a Function of User Actions

\begin{tabular}{|l|c|c|c|}
\cline { 2 - 4 } \multicolumn{1}{c|}{} & $(A)$ Do nothing & $(B)$ Buy & $(C)$ Submit \\
\hline \multirow{2}{*}{ Rival Treatment } & $\left(0, v_{o}+\omega\right)$ & $\left(v_{U}-p, p+\omega\right)$ & $\left(v_{U}, \omega\right)$ \\
& $=(0,2)$ & $=(2,3)$ & $=(4,1)$ \\
\hline \multirow{2}{*}{ Non-rival Treatment } & $\begin{array}{c}\left(0, v_{o}+\omega\right) \\
=(0,2)\end{array}$ & $\begin{array}{c}\left(v_{U}-p, v_{o}+p+\omega\right) \\
=(2,4)\end{array}$ & $\begin{array}{c}\left(v_{U}, v_{o}+\omega\right) \\
=(4,2)\end{array}$ \\
\hline \multirow{2}{*}{ Robustness Treatment } & $\begin{array}{c}\left(0, v_{o}+\omega_{H}\right) \\
=(0,3)\end{array}$ & $\begin{array}{c}\left(v_{U}-p, p+\omega_{H}\right) \\
=(2,4)\end{array}$ & $\begin{array}{c}\left(v_{U}, \omega_{H}\right) \\
=(4,2)\end{array}$ \\
\hline
\end{tabular}

The first entry in the payoff vector is the user's payoff. The table gives the payoffs as a function of the user's action, given that the owner finds a long solution, and the resulting payoffs in US dollar. In the study, $p=2$, $v_{U}=4, s=1, v_{o}=1, \omega=1, \omega_{H}=2$. The table does not include the user's earnings from short solutions, which would be a constant added to the user's payoff in every cell.

$(B)$ Buy $\left(v_{U}+n s-p, v_{o}+p+\omega\right)$; and for $(C)$ Submit $\left(v_{U}+n s, v_{o}+\omega\right)$. Table 1 summarizes the payoffs in the rival and non-rival treatments (the robustness treatment is discussed in section 3.4). Observe that in the non-rival treatment, the owner keeps his induced valuation for the good, $v_{o}$, regardless of the user's action, while in the rival treatment the owner keeps his induced valuation only if the user chooses $(A)$ Do nothing.

\subsection{Procedure}

At the beginning of the sessions, participants are randomly allocated to the role of owner or user. Owners then enter the lab, while users wait for a few minutes to allow the owners to complete the first rounds. Upon entering the lab, users receive comprehensive printed and on-screen instructions. ${ }^{11}$ After reading a handout on the scrabble task, users answer a set of comprehension questions. Users then read a second handout explaining the payoffs and the interaction with the owner before answering another set of comprehension questions. All comprehension questions are implemented such that participants can only move on to the next question after having answered correctly. When stuck, participants can clarify their understanding with the experimenters. In the theft game, one owner is randomly matched

\footnotetext{
${ }^{11}$ The sequence of instructions and screens used are documented in the online supplement to the main sessions.
} 
with a user in each of the 10 rounds. After the main experiment, we administer an incentivized dictator game to elicit social preferences. In addition, we elicit social norms, adapting the incentivized method developed by Krupka and Weber (2013). The sessions conclude with a demographic questionnaire. The experiment is programmed in oTree (Chen et al. 2016). Participants are recruited from the common subject pool of ETH Zurich and the University of Zurich using ORSEE (Greiner 2015).

To calculate the power of our study, we look at a real world analogue of theft of rival versus non-rival goods: According to survey evidence (Poltrack 2013), 40 \% of people consider infringement of intellectual property a serious offense, while $78 \%$ of people think so for infringement of physical property. Guided by this difference of 38 percentage points, our study detects a treatment effect of 30 percentage points, with a power of $80 \%$ and at a significance level of $5 \%$. The non-rival treatment has more participants, as it is employed in two comparisons, one each with the rival and the robustness treatments. The power calculation implies that 37 observations in the rival and 50 observations in the non-rival treatment are required. Note that the number of observations will be lower than the number of users, since a user will sometimes not have a long solution of the owner available. 150 users (and 150 owners) participated in nine main sessions in the ETH Zurich Decision Sciences Laboratory in 2018. The rival treatment has 45 users, the non-rival treatment 60 and the robustness treatment 45 .

\section{Results}

Sessions lasted about 105 minutes for users, and their average earnings were about USD 60 for the session or USD 34 per hour. Demographic characteristics are balanced across treatments. The fraction of users who are female is $0.58(S D=0.5)$ in the rival treatment, $0.60(S D=$ $0.49)$ in the non-rival treatment, and $0.47(S D=0.5)$ in the robustness treatment. The mean age, rounded to one year, is $22(S D=2.6)$ in all three treatments. Users' mean monthly budgets (without rent) are USD $596(S D=487)$ in the rival treatment, USD $501(S D=302)$ 
in the non-rival treatment, and USD $511(S D=380)$ in the robustness treatment. None of these covariates, nor any of the other demographic variables collected, are statistically significant predictors of our outcome variable (see figure A.2 in the appendix).

\subsection{Theft Game}

As mentioned in the introduction, there is no evidence that behavior differs by treatment. Hence, for a first discussion of the theft game as such, particularly regarding how often users choose $(C)$ Submit, we pool the data. Figure 4 plots the fraction of Scrabble tasks where participants solve or claim to solve. The blue curve plots the data from the auxiliary session (where participants can only solve on their own). The red curve plots the data from the main sessions, using data only from user-rounds where a long solution of the owner is available. By comparing both curves, we can investigate whether participants actually solve the Scrabble tasks as often as they claim to. Clearly, users in the main sessions claim to find the long solution independently far more often than users in the auxiliary sessions actually do find it. A two-sided Wilcoxon test rejects the null hypothesis that the distributions are equal ( $W=2977, p=0)$. On average, users in the main sessions claim to find the solution $67 \%$ of the time, while participants in the auxiliary sessions actually find the solution $32 \%$ of the time. Hence, an estimated $35 \%$ of all users steal in a given round or, in other words, about half of all solutions users claim to have found independently are stolen from the owner.

\subsection{Stealing Rival versus Non-rival Goods}

We start our discussion with round 7 , where $0 \%$ of participants in the auxiliary sessions find the long solution before it is shown to them. Hence, we estimate true deniability to be $0 \%$, and can, thus, infer with virtual certainty that a participant who chooses $(C)$ Submit is stealing. Note that, by contrast, in round 7 participants believe, on average, that $34 \%$ of participants find the long solution before it is shown to them. In round 7, $59 \%(S D=0.50)$ of users steal 


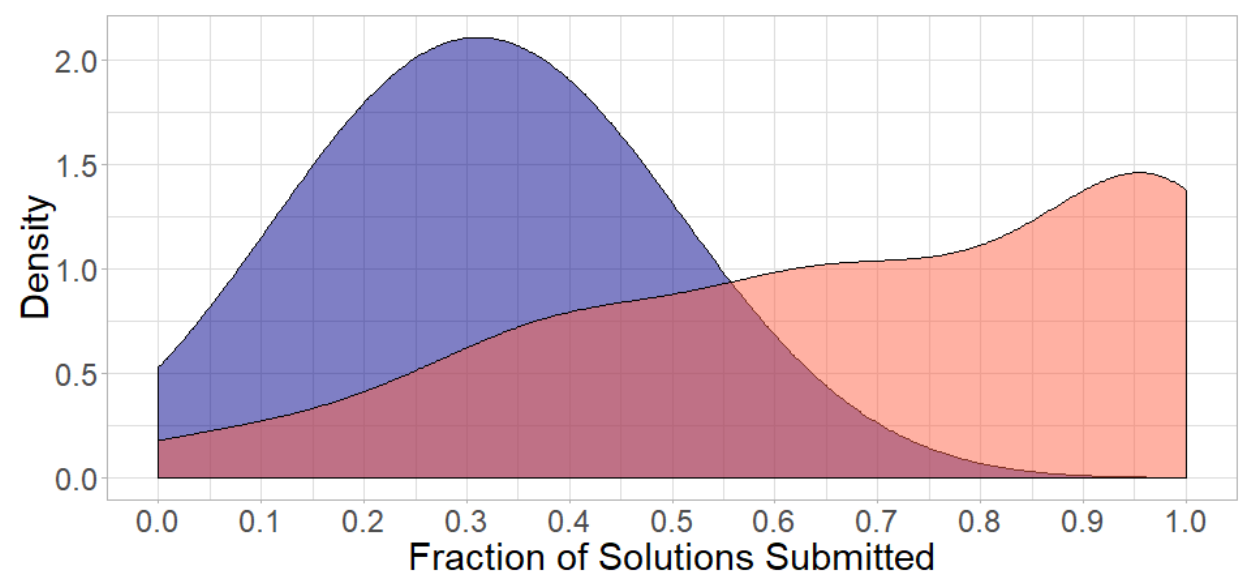

Participants solving independently (auxiliary sessions)

Users choosing (C) Submit (main sessions)

Figure 4: (Claimed) Independent Solutions

The figure shows the density of the fraction of long solutions submitted, participants who have to solve on their own in the auxiliary sessions in blue (see footnote 10) and participants who claim to have solved on their own by choosing $(C)$ Submit in the main sessions in red. The figure uses the Gaussian Kernel smoother with bandwidth 0.1 .

in the rival treatment and $59 \%(S D=0.50)$ steal in the non-rival treatment (figure 5). We cannot reject the null hypothesis that the fraction of users who steal is equal in the rival and non-rival treatments in a two-sided t-test $(t(92.6)=0.02, p=0.98)$. A one-sided Wilcoxon test with the alternative hypothesis that there is less stealing in the rival treatment yields the same conclusion $(W=1301, p=0.51) .{ }^{12}$ In the remaining nine rounds, the fraction of users who steal may differ from the fraction of users who choose $(C)$ Submit. However, if users are more inclined to steal in the non-rival treatment, this results in a higher fraction of users who choose $(C)$ Submit in the non-rival than in the rival treatment. The null hypothesis that behavior is the same in both treatments cannot be rejected in a two-sided Wilcoxon test ( $p=1$, in all ten rounds), independent of the method used to adjust for multiple hypothesis testing (see figure 5). Independent of the covariates used, treatment fixed effects are not a statistically significant predictor of our outcome variable in a regression (see figure A.2 in the appendix). Hence, across all rounds, there is no evidence that the rival or non-rival nature of the good impacts adherence to property rights protecting the good.

\footnotetext{
${ }^{12}$ The same results in a two-sided Wilcoxon test $(W=1301, p=0.98)$.
} 


\section{(A) Do Nothing $\quad$ (B) Buy $\square$ (C) Submit}

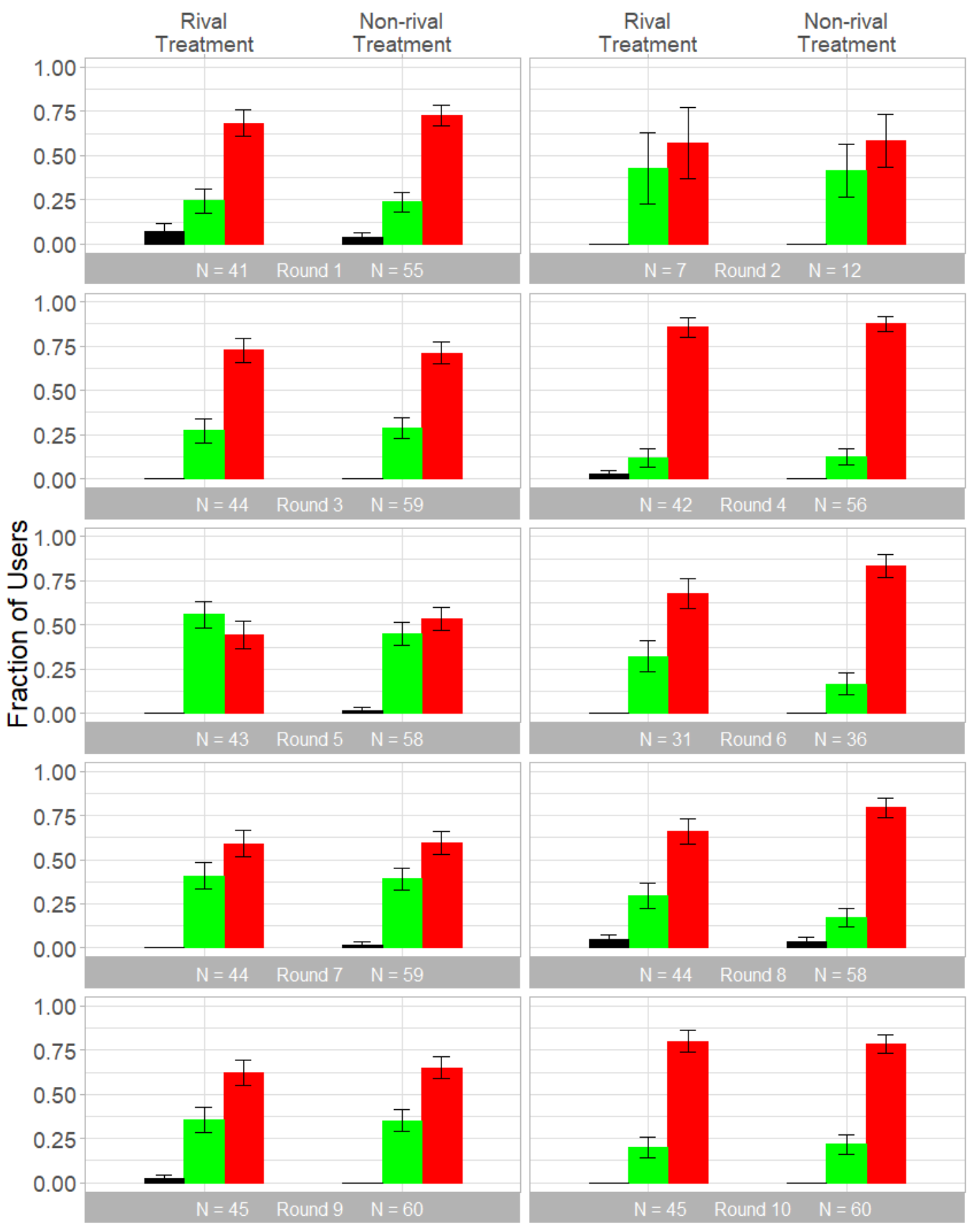

Figure 5: Behavior in the Rival and Non-rival Treatments

The figure presents user behavior by treatment. We only consider the case where a long solution of the owner is available. The error bars show standard errors. 
Failure to reject the null hypothesis does not allow the inference that the null is true (see, for example, Dienes 2014). Hence, we use Bayesian factor analysis to investigate whether the likelihood of the null hypothesis is substantially higher than the likelihood of the alternative. To do so, we follow Gunel and Dickey (1974) and summarize our data in a contingency table. In our case, the rows correspond to the treatments and the columns correspond to behavior. We assume that the counts are multinomially distributed within each row. We use the function contingencyTableBF from the BayesFactor package for R (Morey et al. 2018). For the prior $a$, we use the uninformative prior of $a=1$ (Jamil et al. 2017), which is also the default setting of the function. Using data only from round 7, the resulting Bayes factor is 0.24. According to the classifications of Jeffreys (1939) and Schönbrodt and Wagenmakers (2018), the data thus provides "moderate" evidence in favor of the null hypothesis over the alternative hypothesis. Using the same approach for each round, we find that the data provides evidence in favor of the null over the alternative in every single round. The strength of the evidence is "moderate" in rounds 1, 3, 4, 7, 9 and 10, and "anecdotal" in the remaining rounds. Note that, as Dienes (2011) puts it, "The Bayesian answer does not need to correct for multiple testing." We can provide a single Bayes factor that summarizes the evidence from all ten rounds if we assume independence across rounds. The resulting Bayes factor of 0.20 provides "moderate" evidence in favor of the null.

\subsection{Social Norms}

In addition to observing stealing behavior, we elicit social norms regarding each action of the user. We employ the procedure developed in Krupka and Weber (2013), setting the performance incentive to a highly salient level of USD 10. The instructions request that users imagine a user who did not find the long solution on her own. Then, on separate screens, they indicate how socially appropriate it would be for the user to $(A)$ Do Nothing, $(B)$ Buy or (C) Submit. Participants rate each action as either "very socially inappropriate" (coded as 1),

"somewhat socially inappropriate" (2), "somewhat socially appropriate" (3) or "very socially 
appropriate" (4). Given that the user in this scenario did not find the long solution, action (C) Submit equals stealing.

On average, $(C)$ Submit is rated as $1.47(S D=0.50)$ in the rival treatment and $1.5(S D=$ 0.65) in the non-rival treatment (see figure 6). That corresponds to a rating between "very socially inappropriate" and "somewhat socially inappropriate." The difference in means is not statistically significant in a two-sided Wilcoxon test $(W=1336.5, p=0.92) .{ }^{13}$ We again use Bayesian factor analysis to investigate whether the likelihood of the null hypothesis, that is, that the ratings of social appropriateness are equal across treatments, is substantially higher than that of the alternative. The rows of the contingency tables are the treatments and the four columns correspond to the ratings of the social appropriateness of choosing $(C)$ Submit. The resulting Bayes factor of 0.01 provides "very strong" evidence for the null over the alternative. On average, $(A)$ Do nothing is rated as $2.84(S D=0.85)$ in the rival treatment and 2.48 $(S D=0.83)$ in the non-rival treatment, while $(B)$ Buy is rated as $3.71(S D=0.46)$ in the rival treatment and $3.77(S D=0.43)$ in the non-rival treatment. Clearly, for our participants, stealing is the only action that is socially inappropriate (see figure A.4 in the appendix for the figures for actions $(A)$ and $(B))$. In a regression, viewing stealing as less socially inappropriate is a statistically significant predictor of stealing (see figure A.2 in the appendix).

\subsection{Robustness Treatment: Outcome-based Preferences}

We do not find any evidence that the non-rival nature of a good has an impact on adherence to property rights protecting the good. In this section, we investigate whether such an effect exists but is obscured by outcome-based preferences. To see how this could be the case, consider the following: If a user chooses $(C)$ Submit in the rival treatment, this will decrease the owner's payoff, while it will not in the non-rival treatment. Thereby, the type of good has

\footnotetext{
${ }^{13}$ The same results in a one-sided Wilcoxon test with alternative hypothesis that stealing is seen as more inappropriate in the rival treatment $(W=1336.5, p=0.46)$ and in a two-sided t-test $(t(102.9)=0.30, p=$ $0.77)$.
} 


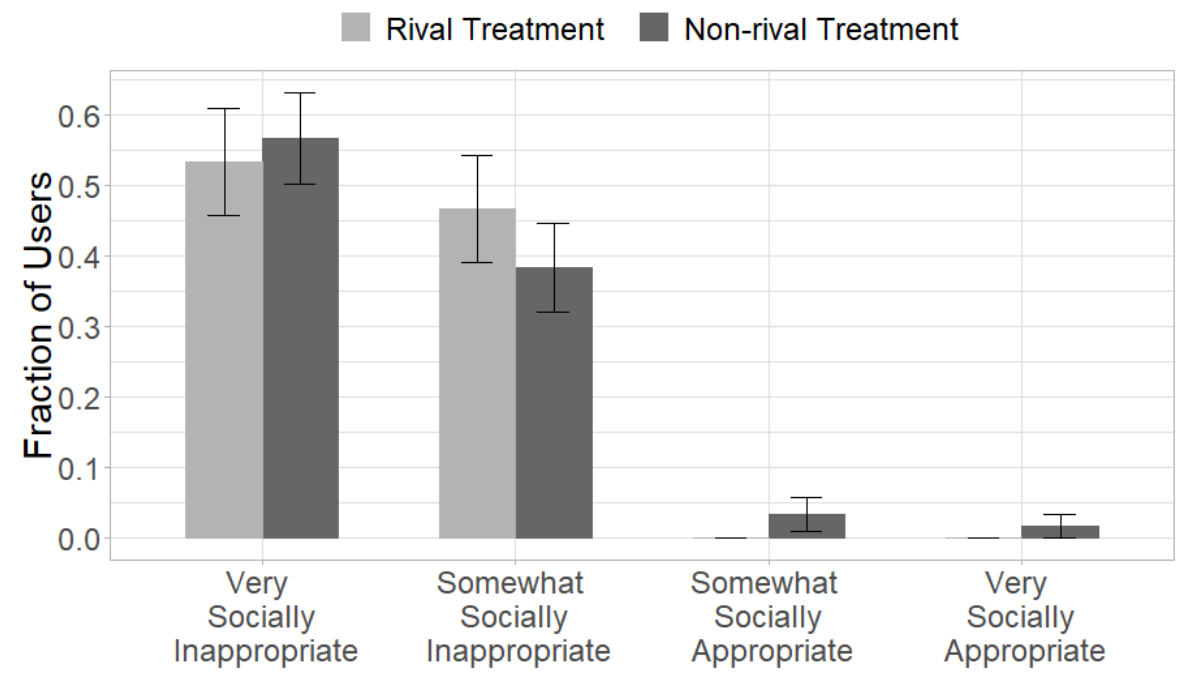

Figure 6: Social Appropriateness of Stealing

We measure participants' beliefs about how appropriate others view stealing (from 1 "very socially inappropriate" to 4 "very socially appropriate"). The figure presents results for the rival and non-rival treatments. Given that we ask participants to judge the scenario where the user did not find the long solution on his own, action $(C)$ Submit equals stealing. The error bars show standard errors.

an impact on the owner's payoff. User behavior could vary between treatments because of the differential impact of stealing on the owner's payoff. A null effect might then not be due to the treatments causing no difference but rather due to two forces offsetting each other, the nature of the good and outcome-based preferences.

To investigate this possibility, we conduct a robustness treatment in which the endowment of the owner exactly offsets the payoff differences arising from the nature of the good. The robustness treatment employs a rival good, and an additional owner endowment set such that the treatment differs from the non-rival treatment only in the nature of the good. Specifically, the owner is endowed with $\omega_{H}=\omega+v_{o}$. Thus, if the user chooses $(B)$ Buy in the robustness treatment, the resulting payoff for the owner is $\omega_{H}+p$, which equals his payoff of $\omega+v_{o}+p$ in the non-rival treatment. If the user chooses $(C)$ Submit in the robustness treatment, then the owner payoff is $\omega_{H}$, which is equal to his payoff of $\omega+v_{o}$ in the non-rival treatment (see table 1). The payoff of the user is the same across all treatments. Note that if the user was solely driven by outcome-based preferences, her behavior should not differ between the 
robustness and the non-rival treatments, as the payoff for both the user and the owner are independent of the treatment. If we observe a treatment difference in this setup, it cannot be explained by outcome-based preferences but must be due to the nature of the good. ${ }^{14}$ As in our main experiment, we also elicit social norms.

We cannot reject the null hypothesis that behavior is the same in the non-rival and the robustness treatment (see figure A.3 in the appendix). The p-value essentially equals 1 for each round, independent of the method used to adjust for multiple hypothesis testing. Hence, there is no evidence that our main finding can be explained by outcome-based preferences. We again use Bayesian factor analysis. Round 2 employs such a difficult scramble that there are only 11 observations in the robustness and 12 observations in the non-rival treatment (versus an average of 40 and 56 observations, respectively, in the other rounds). In this round we find "anecdotal" evidence in favor of the alternative hypothesis. All other rounds provide "anecdotal" or "moderate" evidence in favor of the null. Assuming independence across rounds, the Bayes factor from all rounds provides "anecdotal" evidence for the null. Regarding social norms, stealing is, on average, rated as $1.60(S D=0.75)$ in the robustness treatment, which is not statistically significantly different from the rating in the non-rival treatment. ${ }^{15}$ Bayesian factor analysis provides "very strong" evidence for the null hypothesis that there is no difference in participants' ratings of the social appropriateness of choosing $(C)$ Submit across treatments. $(A)$ Do nothing is rated as $2.78(S D=0.82)$ and $(B)$ Buy is rated as 3.6 $(S D=0.65)$ (see figure A.5 in the appendix).

\footnotetext{
${ }^{14}$ For $(A)$ Do Nothing, the owner's payoff differs between the non-rival and the robustness treatments. However, option $(A)$ is strictly Pareto-dominated and, empirically, users only choose this option about $2 \%$ of the time.

${ }^{15}$ Two-sided Wilcoxon test $(W=1272.5, p=0.57)$. The same results in a one-sided Wilcoxon test with the alternative hypothesis that stealing is seen as more inappropriate in the rival treatment $(W=1272.5, p=0.29)$, and in a two-sided t-test $(t(87)=-0.72, p=0.48)$.
} 


\subsection{Discussion}

This study investigates one factor that could explain why people have less respect for intellectual than for physical property: While physical property rights protect rival goods, intellectual property rights protect non-rival goods. To cleanly isolate the effect of (non-)rivalry on behavior and social norms, we conduct a laboratory experiment. We find no evidence that people differentiate between rival and non-rival goods, neither in behavior nor in social norms. However, it is a commonly and strongly held prior that intellectual property rights are substantially more infringed upon, and that this is also reflected in social norms. This raises the question whether there are factors that cast doubt on our results.

First, one might wonder whether our findings could be explained by inadequate participant understanding. However, participants receive instructions both verbally and in writing. Users have to answer nine comprehension questions correctly before the theft game. Participants can individually ask the experimenters questions at any time. In the main sessions, we conducted exit interviews with random subsamples of participants. From these interviews, we are confident that participants fully understand the game. Second, the treatment consists of different payoff consequences for the owner regarding buying and theft. The payoff consequences are made salient to the user using several measures. They are described in detailed instructions and several comprehension questions are dedicated to them. In addition, the payoff consequences for both players are repeated on the screen where users choose an action and, upon selecting an action, they are highlighted in red text (see figure 2). After each round, the user receives a screen giving the payoff consequences arising from her action regarding the long solution for both participants. Third, owner behavior cannot explain the results regarding user behavior, as owners are randomly allocated to treatments and do not know in which treatment they are. To that end, instructions for owners do not include the exact payoff consequences of users' behavior. Fourth, the results are not due to insufficient monetary payoffs for users. Incentives are extremely salient, with the average user earning more than $10 \%$ of her monthly 
budget (without rent) in less than two hours. Finally, the results cannot be explained by unusual social preferences in our subject pool. To benchmark our participants to the previous literature, we run a simple dictator game after the main experiment. Users decide how much of two US dollars (in USD 0.1 increments) they want to keep for themselves. The remainder is allocated to another, randomly matched participant. On average, users keep USD 1.39, or about $70 \%$ of the pie, and $77 \%$ of users allocate some money to the other participant. ${ }^{16}$ The result is comparable to the previous literature, where dictators typically keep about $80 \%$ of the pie, and somewhat more than $60 \%$ of dictators transfer some money (Levitt and List 2007).

\section{Conclusion}

There is an economically and ethically very relevant difference between physical property and intellectual property: The former is rival, while the latter is not. Taking someone else's nonrival property does not enjoin them from consuming the good themselves or letting others do so. This paper examines whether this difference can explain why there is less respect for intellectual property rights than for physical property rights. Our paper employs a laboratory experiment to isolate this potential explanation from other explanations. This allows us to keep all factors constant across control and treatment except the nature of the good. In order to address our research question, we design a new theft game. Existing lab studies on theft typically employ (framed) dictator games. Compared to such studies, the theft game has three advantageous features: First, participants perceive theft as plausibly deniable vis-à-vis both the victim and the experimenter. Second, the possibility of stealing does not appear as a deliberate option given by the experimenter but rather as arising naturally. Third, deniability as perceived by the participant differs from true deniability. This design allows us to infer stealing with near certainty (in round 7), while participants believe that they can plausibly

\footnotetext{
${ }^{16} \mathrm{In}$ a regression, dictator keeping is a statistically significant predictor of stealing (see figure A.2 in the appendix).
} 
deny stealing.

Despite high perceived plausible deniability and the absence of sanctions, participants in our theft game steal only about one out of two times when given the possibility. This incidental result of our study strengthens findings of the previous literature that there is substantial voluntary adherence to property rights (see, for example, Levitt and List 2007; List 2007). To address our core research question, we implement a rival treatment and a non-rival treatment. In the rival treatment, the owner cannot consume the good if he sells it or if it is stolen, while he can in the non-rival treatment. Users (the potential thieves) are fully aware of this and the associated payoff consequences for the owner (the potential victim). However, the null hypothesis that stealing behavior is identical across treatments cannot be rejected. Using Bayesian factor analysis, we find evidence for the null hypothesis over the alternative hypothesis in all ten rounds. Hence, we find evidence that participants see the rival versus non-rival nature of a good as irrelevant to their behavior towards others' property. Behavior is reflected in social norms. Using the incentivized Krupka-Weber method, we find that social norms concerning theft of rival goods do not differ from those concerning non-rival goods. Given our prior that people have less respect for property rights in non-rival goods, the findings are very unexpected. However, all results point in the same direction. The experiment was saliently incentivized, and numerous exit interviews make us confident that participants understood the experimental procedures.

Whether people view physical and intellectual property differently is a key question for policymakers. While it may be intuitive that adherence to intellectual property norms is lower than for physical property norms, this is subject to debate both as a normative and descriptive matter. Easterbrook (1990) argues that "Intellectual Property is Still Property," and that both types of property should be treated identically in law. Following this line of thought, scholars have argued that intellectual property is, descriptively, the same as physical property and, normatively, should be treated similarly (see Smith 2007; Merges 2018; but see Lemley 2014; Cohen 2015). By contrast, Tyler (1997) argues that people have less respect for intellectual 
than for physical property. Depoorter et al. (2011, 2015) argue that effective deterrence may not be achieved in societies where copyright infringement is widespread without raising enforcement to a level which undermines society's support for the underlying copyright rules.

Our evidence can inform these debates regarding one important dimension. Physical and intellectual property differ on many dimensions, and our lab study isolates a single dimension, the rival versus non-rival nature of goods. All other dimensions are kept constant. The results casts doubt on the notion that law should treat physical and intellectual property differently due to differing social or intrinsic norms regarding the rivalry of the protected good. Our interpretation of the data is that the difference in direct harm to the owner by the infringement of a rival versus a non-rival good does not cause humans to adapt differential behavior or social norms. However, it may well be the case that this dimension in combination with another one, for example whether the owner is likely to notice theft and feel victimized, could explain real world behavior.

Or study does not analyze other dimensions in which physical and intellectual property also differ. In our study, for instance, across all treatments, there is a zero probability of punishment, goods are intangible and owners never learn for sure whether they were victimized. In these dimensions, the lab experiment does not model typical differences between physical and intellectual property found in the real world: Typically, physical property owners are not monopolists, the property is tangible, theft or loss is noticed, the detection probability is high and punishments are comparatively harsh. By contrast, intellectual property owners are often monopolists, the property is intangible, theft easily goes unnoticed, the detection probability is low and punishments are comparatively weak. We see two promising avenues for future research: First, whether a good is tangible or not. Second, whether the user believes the owner notices harmful infringement or not. While our study isolates the rivalry dimension, future research could examine the causal impact of these additional dimensions. 


\section{References}

Al-Rafee, S. and T. P. Cronan (2006). Digital piracy: Factors that influence attitude toward behavior. Journal of Business Ethics 63, 237-259.

Armstrong, A., J. Mueller, and T. Syrett (2014). The smartphone royalty stack: Surveying royalty demands for the components within modern smartphones. www.wilmerhale.com/en/insights/publications/the-smartphone-royalty-stack.

Athey, S. and S. Stern (2015). The nature and incidence of software piracy: Evidence from Windows. In A. Goldfarb, S. M. Greenstein, and C. E. Tucker (Eds.), Economic Analysis of the Digital Economy, pp. 443-477. Chicago: University of Chicago Press.

Barnett, J. (2005). Shopping for Gucci on Canal Street: Reflections on status consumption, intellectual property, and the incentive thesis. Virginia Law Review 91, 1381-1423.

Baumann, F. and T. Friehe (2017). Crime and punishment under evidentiary uncertainty: Laboratory evidence. Supreme Court Economic Review 25(1), 65 - 104.

Bechtold, S., C. Buccafusco, and C. J. Sprigman (2016). Innovation heuristics: Experiments on sequential creativity in intellectual property. Indiana Law Journal 91, 1251-1307.

Becker, G. S. (1968). Crime and punishment: An economic approach. Journal of Political Economy 76, 169-217.

Brüggemann, J., P. Crosetto, L. Meub, and K. Bizer (2016). Intellectual property rights hinder sequential innovation: Experimental evidence. Research Policy 45, 2054-2068.

Brüggemann, J. and L. Meub (2017). Experimental evidence on the effects of innovation contests. Information Economics and Policy 39, 72-83.

Buccafusco, C. and J. S. Masur (2013). Innovation and incarceration: An economic analysis of criminal intellectual property law. Southern California Law Review 87, 275-334.

Buonanno, P., D. Montolio, and P. Vanin (2009). Does social capital reduce crime? Journal of Law \& Economics 52, 145-170.

Chen, D. L., M. Schonger, and C. Wickens (2016). oTree - An open-source platform for laboratory, online, and field experiments. Journal of Behavioral and Experimental Finance 9, $88-97$. 
Cohen, J. E. (2015). Property as institutions for resources: Lessons from and for IP. Texas Law Review 94, 1-57.

Contreras, J. (2019). Technical standards, standard-setting organizations and intellectual property: A survey of the literature. In P. Menell and D. Schwartz (Eds.), Research Handbook on the Economics of Intellectual Property Law, Volume II. Cheltenham: Edward Elgar.

Crosetto, P. (2010). To patent or not to patent: A pilot experiment on incentives to copyright in a sequential innovation setting. In P. Agerfalk, C. Boldyreff, J. M. Gonzalez-Barahona, G. R. Madey, and J. Noll (Eds.), Open Source Software: New Horizons - 6th International IFIP WG 2.13 Conference on Open Source Systems, OSS 2010 Notre Dame, pp. 53-72. Springer.

Day, G. and S. Udick (2019). Patent law and the emigration of innovation. Washington Law Review 94, 119-170.

de Quidt, J., J. Haushofer, and C. Roth (2018). Measuring and bounding experimenter demand. American Economic Review 108, 3266-3302.

Dedrick, J. and K. Kraemer (2017). Intangible assets and value capture in global value chains: the smartphone industry. Economic Research Working Paper No. 41, World Intellectual Property Organization.

Depoorter, B. and A. Van Hiel (2015). Copyright alert enforcement: Six strikes and privacy harms. Columbia Journal of Law and the Arts 39, 233-277.

Depoorter, B., A. Van Hiel, and S. Vanneste (2011). Copyright backlash. Southern California Law Review 84, 1251-1292.

Dienes, Z. (2011). Bayesian versus orthodox statistics: Which side are you on? Perspectives on Psychological Science 6, 274-290.

Dienes, Z. (2014). Using Bayes to get the most out of non-significant results. Frontiers in Psychology 5, 781 .

Easterbrook, F. H. (1990). Intellectual property is still property. Harvard Journal of Law \& Public Policy 13, 108-118.

Engel, C. (2016). A random shock is not random assignment. Economics Letters 145, 45-47.

Engel, C. and D. Nagin (2015). Who is afraid of the stick? Experimentally testing the deterrent effect of sanction certainty. Review of Behavioral Economics 2, 405-434. 
Faillo, M., M. Rizzolli, and S. Tontrup (2018). Thou shalt not steal: Taking aversion with legal property claims. Journal of Economic Psychology 71, 88-101.

Fairphone (2015). Cost breakdown of the Fairphone 2. www.fairphone.com/wpcontent/uploads/2015/09/Fairphone2-Cost-Breakdown.pdf.

Falk, A. and U. Fischbacher (2002). Crime in the lab: Detecting social interaction. European Economic Review 46, 859-869.

Fast, A. A., K. R. Olson, and G. N. Mandel (2017). Intuitive intellectual property law: A nationally-representative test of the plagiarism fallacy. PLOS ONE 12, 1-11.

Feess, E., H. Schildberg-Hörisch, M. Schramm, and A. Wohlschlegel (2018). The impact of fine size and uncertainty on punishment and deterrence: Theory and evidence from the laboratory. Journal of Economic Behavior \& Organization 149, 58-73.

Fischbacher, U. and F. Föllmi-Heusi (2013). Lies in disguise - An experimental study on cheating. Journal of the European Economic Association 11, 525-547.

Fleming, P., M. Parravano, and D. J. Zizzo (2016). To pay or not to pay? Determinants of unlawful product acquisition. CREATe Working Paper Series 2016/01.

Fleming, P., S. J. Watson, E. Patouris, K. J. Bartholomew, and D. J. Zizzo (2017). Why do people file share unlawfully? A systematic review, meta-analysis and panel study. Computers in Human Behavior 72, 535-548.

Galetovic, A., S. Haber, and L. Zaretzki (2018). An estimate of the average cumulative royalty yield in the world mobile phone industry: Theory, measurement and results. Telecommunications Policy 42, 263-276.

Goel, R. K. and M. A. Nelson (2009). Determinants of software piracy: Economics, institutions, and technology. Journal of Technology Transfer 34, 637-658.

Graham, S. and S. Vishnubhakat (2013). Of smart phone wars and software patents. Journal of Economic Perspectives 27, 67-86.

Gravert, C. (2013). How luck and performance affect stealing. Journal of Economic Behavior \& Organization 93, 301-304.

Green, S. P. and M. B. Kugler (2010). Community perceptions of theft seriousness: A challenge to model penal code and English Theft Act consolidation. Journal of Empirical Legal Studies 7, 511-537. 
Greiner, B. (2015). Subject pool recruitment procedures: Organizing experiments with ORSEE. Journal of the Economic Science Association 1, 114-125.

Gunel, E. and J. Dickey (1974). Bayes factors for independence in contingency tables. Biometrika $61,545-557$.

Harbaugh, W. T., N. Mocan, and M. S. Visser (2013). Theft and deterrence. Journal of Labor Research 34, 389-407.

Hergueux, J. and D. Jemielniak (2019). Should digital files be considered a commons? Copyright infringement in the eyes of lawyers. Information Society 35, 198-215.

Hoffman, E., K. McCabe, S. Keith, and S. Vernon (1994). Preferences, property rights, and anonymity in bargaining games. Games and Economic Behavior 7, 346-380.

Jamil, T., A. Ly, R. D. Morey, J. Love, M. Marsman, and E.-J. Wagenmakers (2017). Default "Gunel and Dickey" Bayes factors for contingency tables. Behavior Research Methods 49, $638-652$.

Jeffreys, H. (1939). Theory of Probability. Oxford: Clarendon Press.

Kajackaite, A. and U. Gneezy (2017). Incentives and cheating. Games and Economic Behavior 102, 433-444.

Kettner, S. E. and S. Ceccato (2014). Framing matters in gender-paired dictator games. Discussion Paper Series No. 557, University of Heidelberg, Department of Economics.

Kettner, S. E. and I. Waichman (2016). Old age and prosocial behavior: Social preferences or experimental confounds? Journal of Economic Psychology 53, 118-130.

Khadjavi, M. (2015). On the interaction of deterrence and emotions. Journal of Law, Economics $\&$ Organization 31, 287-319.

Khadjavi, M. (2018). Deterrence Works for Criminals. European Journal of Law ES Economics 46, 165-178.

Krawczyk, M., J. Tyrowicz, A. Kukla-Gryz, and W. Hardy (2015). Piracy is not theft - Is it just students who think so? Journal of Behavioral and Experimental Economics 54, 32-39.

Krupka, E. L. and R. A. Weber (2013). Identifying social norms using coordination games: Why does dictator game sharing vary? Journal of the European Economic Association 11, $495-524$. 
Landes, W. M. and R. A. Posner (2003). The Economic Structure of Intellectual Property Law. Cambridge: Harvard University Press.

LaRose, R. and J. Kim (2007). Share, steal, or buy? A social cognitive perspective of music downloading. Cyberpsychology \& Behavior 10, 267-277.

LaRose, R., Y. J. Lai, R. Lange, B. Love, and Y. Wu (2005). Sharing or piracy? An exploration of downloading behavior. Journal of Computer-Mediated Communication 11, 1-21.

Lemley, M. A. (2014). Taking the regulatory nature of IP seriously. Texas Law Review 92, 107-119.

Levitt, S. D. and J. A. List (2007). What do laboratory experiments measuring social preferences reveal about the real world? Journal of Economic Perspectives 21, 153-174.

Li, X. and N. Nergadze (2009). Deterrence effect of four legal and extralegal factors on online copyright infringement. Journal of Computer-Mediated Communication 14, 307-327.

Liao, C., H.-N. Lin, and Y.-P. Liu (2010). Predicting the use of pirated software: A contingency model integrating perceived risk with the theory of planned behavior. Journal of Business Ethics 91, 237-252.

List, J. A. (2007). On the interpretation of giving in dictator games. Journal of Political Economy 115, 482-493.

Lysonski, S. and S. Durvasula (2008). Digital piracy of MP3s: Consumer and ethical predispositions. Journal of Consumer Marketing 25, 167-178.

Mallinson, K. (2015). Smartphone revolution: Technology patenting and licensing fosters innovation, market entry, and exceptional growth. IEEE Consumer Electronics Magazine 4, 60-66.

Mandel, G. N., A. A. Fast, and K. R. Olson (2015). Intellectual property law's plagiarism fallacy. Brigham Young University Law Review 915, 915-984.

Manesh, M. (2006). The immorality of theft, the amorality of infringement. Stanford Technology Law Review, 5.

Merges, R. (2018). What kind of rights are intellectual property rights? In R. C. Dreyfuss and J. Pila (Eds.), The Oxford Handbook on Intellectual Property Law, pp. 57-94. Oxford University Press. 
Morey, R. D., J. N. Rouder, T. Jamil, S. Urbanek, K. Forner, and A. Ly (2018). BayesFactor: Computation of Bayes Factors for common designs. R package version 0.9.12-4.2.

Paik, Y. and F. Zhu (2016). The impact of patent wars on firm strategy: Evidence from the global smartphone industry. Organization Science 27, 1397-1416.

Pecenka, C. J. and G. Kundhlande (2013). Theft in South Africa: An experiment to examine the influence of racial identity and inequality. Journal of Development Studies 49, 737-753.

Poltrack, A. (2013). Pirated TV: How it works and why it can't be stopped. Digital Trends. www.digitaltrends.com/home-theater/pirated-tv-can-and-should-it-be-stopped/.

Rhode, D. L. (2019). Cheating: Ethics in Everyday Life. Oxford: Oxford University Press.

Rizzolli, M. and L. Stanca (2012). Judicial errors and crime deterrence: Theory and experimental evidence. Journal of Law \& Economics 55, 311-338.

Schildberg-Hörisch, H. and C. Strassmair (2012). An experimental test of the deterrence hypothesis. Journal of Law, Economics $\&$ Organization 28, 447-459.

Schönbrodt, F. D. and E.-J. Wagenmakers (2018). Bayes factor design analysis: Planning for compelling evidence. Psychonomic Bulletin \& Review 25, 128-142.

Sidak, J. G. (2016). What aggregate royalty do manufacturers of mobile phones pay to license standard-essential patents? Criterion: Journal on Innovation 1, 701-719.

Smith, H. E. (2007). Intellectual property as property: Delineating entitlements in information. Yale Law Journal 116, 1742-1822.

Solow, R. M. (1987). Growth theory and after. Nobel Prize Lecture. www.nobelprize.org/prizes/economic-sciences/1987/solow/lecture/.

Tyler, T. R. (1997). Compliance with the intellectual property laws: A psychological perspective. New York University Journal of International Law \& Politics 29, 219-235.

van der Ende, M., J. Poort, R. Haffner, P. de Bas, A. Yagafarova, S. Rohlfs, and H. van Til (2014). Estimating displacement rates of copyrighted content in the EU. European Commission. https://publications.europa.eu/en/publication-detail/-/publication/59ea4ec1-a19b11e7-b92d-01aa75ed71a1.

Watson, S. J., D. J. Zizzo, and P. Fleming (2015). Determinants of unlawful file sharing: A scoping review. PLOS ONE 10,1-23. 
Williams, P., D. Nicholas, and I. Rowlands (2010). The attitudes and behaviours of illegal downloaders. Aslib Proceedings 62, 283-301.

Wingrove, T., A. L. Korpas, and V. Weisz (2011). Why were millions of people not obeying the law? Motivational influences on non-compliance with the law in the case of music piracy. Psychology, Crime 85 Law 17, 261-276.

World Intellectual Property Organization (2017). Intangible capital in global value chains. www.wipo.int/publications/en/details.jsp?id=4225.

Zizzo, D. J. (2010). Experimenter demand effects in economic experiments. Experimental Economics 13, 75-98. 


\section{Appendix}

\begin{tabular}{|c|c|c|}
\hline \multicolumn{3}{|c|}{$\begin{array}{l}\text { You have three options regarding JOYFULLY: } \\
\text { (A) Do nothing }\end{array}$} \\
\hline \multicolumn{3}{|c|}{ If you buy and submit (B), or submit without buying (C), you and the green participant will both receive money for JOYFULLY. } \\
\hline \multicolumn{3}{|c|}{$\begin{array}{l}\text { Regarding option (C): We cannot determine whether you really arrived at this solution on your own. Thus, your decision alone } \\
\text { determines your earnings and the earnings of the green participant for JOYFULLY. }\end{array}$} \\
\hline (A) Do nothing & (B) Buy and submit & (C) Submit without buying \\
\hline You: CHF 0. & $\begin{array}{l}\text { You: CHF } 4 \text { for JOYFULLY minus the } \\
\text { price of CHF 2, hence CHF } 2 \text {. }\end{array}$ & You: CHF 4 for JOYFULLY. \\
\hline $\begin{array}{l}\text { Green participant: CHF } 1 \text { for } \\
\text { JOYFULLY plus CHF } 1 \text { round wage, } \\
\text { hence CHF } 2 \text {. }\end{array}$ & $\begin{array}{l}\text { Green participant: CHF } 1 \text { for } \\
\text { JOYFULLY, the price of CHF } 2 \text { plus } \\
\text { CHF } 1 \text { round wage, hence CHF } 4 \text {. }\end{array}$ & $\begin{array}{l}\text { Green participant: CHF } 1 \text { for } \\
\text { JOYFULLY plus CHF } 1 \text { round wage, } \\
\text { hence CHF } 2 \text {. }\end{array}$ \\
\hline \multicolumn{3}{|c|}{$\begin{array}{l}\text { Please note: If you have entered other solutions on the previous screen, you receive additional money for those. The green } \\
\text { participant cannot enter other solutions. }\end{array}$} \\
\hline \multicolumn{3}{|c|}{$\begin{array}{l}\text { If you choose }(\mathrm{C}) \text {, you submit JOYFULLY without } \\
\text { buying this solution. The green participant also } \\
\text { submits this solution, but does not receive the } \\
\text { price from you. }\end{array}$} \\
\hline
\end{tabular}

Figure A.1: Do Nothing, Buy, or Steal? (Non-rival Treatment)

The figure shows the screen of the user in the baseline treatment facing the decision between $(A)$ Do nothing, $(B)$ Buy and $(C)$ Submit. In the example shown, the owner has found the long solution JOYFULLY, and the user is selecting $(C)$ Submit. After users have selected $(A),(B)$, or $(C)$, the red text reminds them of the consequences for the owner. If the user had chosen $(A)$ Do nothing, the red confirmation text would be "If you choose $(A)$, you neither buy JOYFULLY nor submit this solution without buying it," if she had chosen $(B)$ Buy, the red text would be "If you choose $(B)$ you buy JOYFULLY and submit this solution. The green participant also submits this solution and receives the price from you." 


\begin{tabular}{|c|c|c|c|}
\hline & \multicolumn{3}{|c|}{ Dependent variable: } \\
\hline & \multicolumn{3}{|c|}{ Submit } \\
\hline & (1) & $(2)$ & (3) \\
\hline Rival Treatment & $\begin{array}{l}-0.042 \\
(0.058)\end{array}$ & $\begin{array}{l}-0.042 \\
(0.057)\end{array}$ & $\begin{array}{c}-0.044 \\
(0.046)\end{array}$ \\
\hline Robustness Treatment & $\begin{array}{l}-0.063 \\
(0.053)\end{array}$ & $\begin{array}{l}-0.064 \\
(0.054)\end{array}$ & $\begin{array}{l}-0.033 \\
(0.048)\end{array}$ \\
\hline Male & & $\begin{array}{c}0.048 \\
(0.049)\end{array}$ & $\begin{array}{c}0.061 \\
(0.040)\end{array}$ \\
\hline Age & & $\begin{array}{l}-0.006 \\
(0.010)\end{array}$ & $\begin{array}{l}-0.010 \\
(0.008)\end{array}$ \\
\hline Non-Swiss & & $\begin{array}{l}-0.059 \\
(0.055)\end{array}$ & $\begin{array}{l}-0.063 \\
(0.045)\end{array}$ \\
\hline Monthly Budget & & & $\begin{array}{l}-0.00002 \\
(0.00004)\end{array}$ \\
\hline Non-ETH Student & & & $\begin{array}{c}0.043 \\
(0.050)\end{array}$ \\
\hline Law Student & & & $\begin{array}{c}0.173^{* *} \\
(0.085)\end{array}$ \\
\hline Scrabble Ability & & & $\begin{array}{l}-0.004 \\
(0.003)\end{array}$ \\
\hline Dictator Sharing & & & $\begin{array}{c}-0.343^{* * *} \\
(0.041)\end{array}$ \\
\hline Social Appropriateness & & & $\begin{array}{c}0.064^{* * *} \\
(0.024)\end{array}$ \\
\hline Observations & 1,297 & 1,297 & 1,297 \\
\hline $\mathrm{R}^{2}$ & 0.003 & 0.009 & 0.142 \\
\hline Adjusted $\mathrm{R}^{2}$ & 0.002 & 0.005 & 0.133 \\
\hline Residual Std. Error & $0.466(\mathrm{df}=1294)$ & $0.465(\mathrm{df}=1291)$ & $0.434(\mathrm{df}=1282)$ \\
\hline
\end{tabular}

Figure A.2: Regression Results

The figure presents OLS-results from a linear probability model. Column(1) only regresses on treatment fixed effects with the non-rival treatment as baseline, column (2) includes key demographic covariates, and column (3) includes further covariates. The dependent variable is a binary variable indicating whether a participant did or did not choose $(C)$ Submit in a given round, provided the owner had found the long solution. Each participantround is one observation, standard errors are clustered on the participant level. Age is participant age in years. Non-Swiss refers to the participant's nationality, relative to the baseline of Swiss participants. Monthly budget is the participant's monthly budget in US dollars, excluding rent. Non-ETH students are students at other institutions than the Federal Institute of Technology, primarily at the University of Zurich. Law students are compared to the baseline of STEM students, while the coefficients for students whose field is unknown and for non-students are omitted. Scrabble ability is the total number of short solutions (five to seven letters) submitted. Dictator sharing is the amount (out of an endowment of USD 2) transferred to the owner in a standard dictator game. Social Appropriateness is participant's judgment of how socially appropriate others view stealing (from 1 "very socially inappropriate" to 4 "very socially appropriate"). 
(A) Do Nothing $\quad$ (B) Buy $\square$ (C) Submit

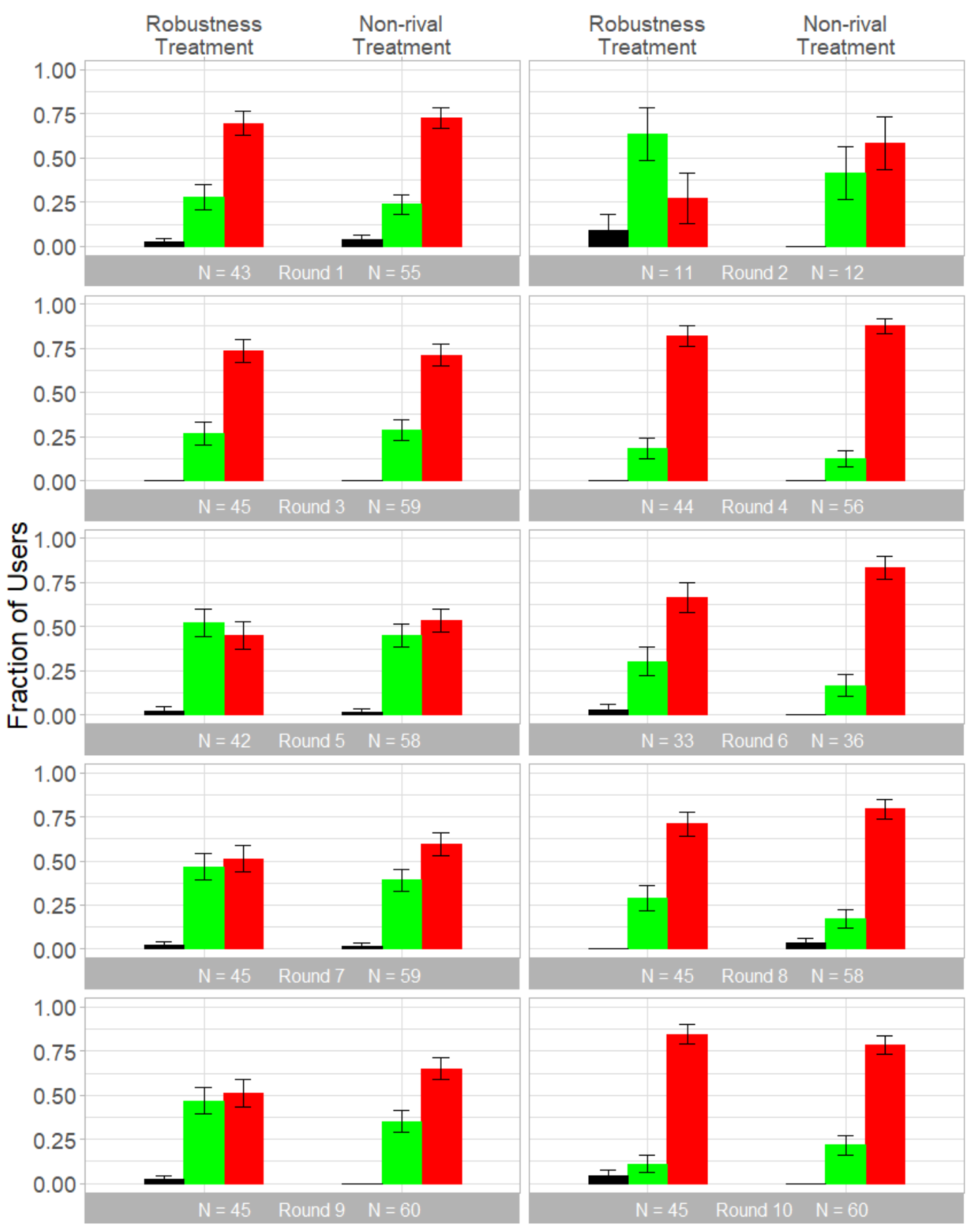

Figure A.3: Behavior in the Robustness and Non-rival Treatments

The figure presents user behavior by treatment. We only consider the case where a long solution of the owner is available. The error bars show standard errors. 


\section{Rival Treatment $\square$ Non-rival Treatment}

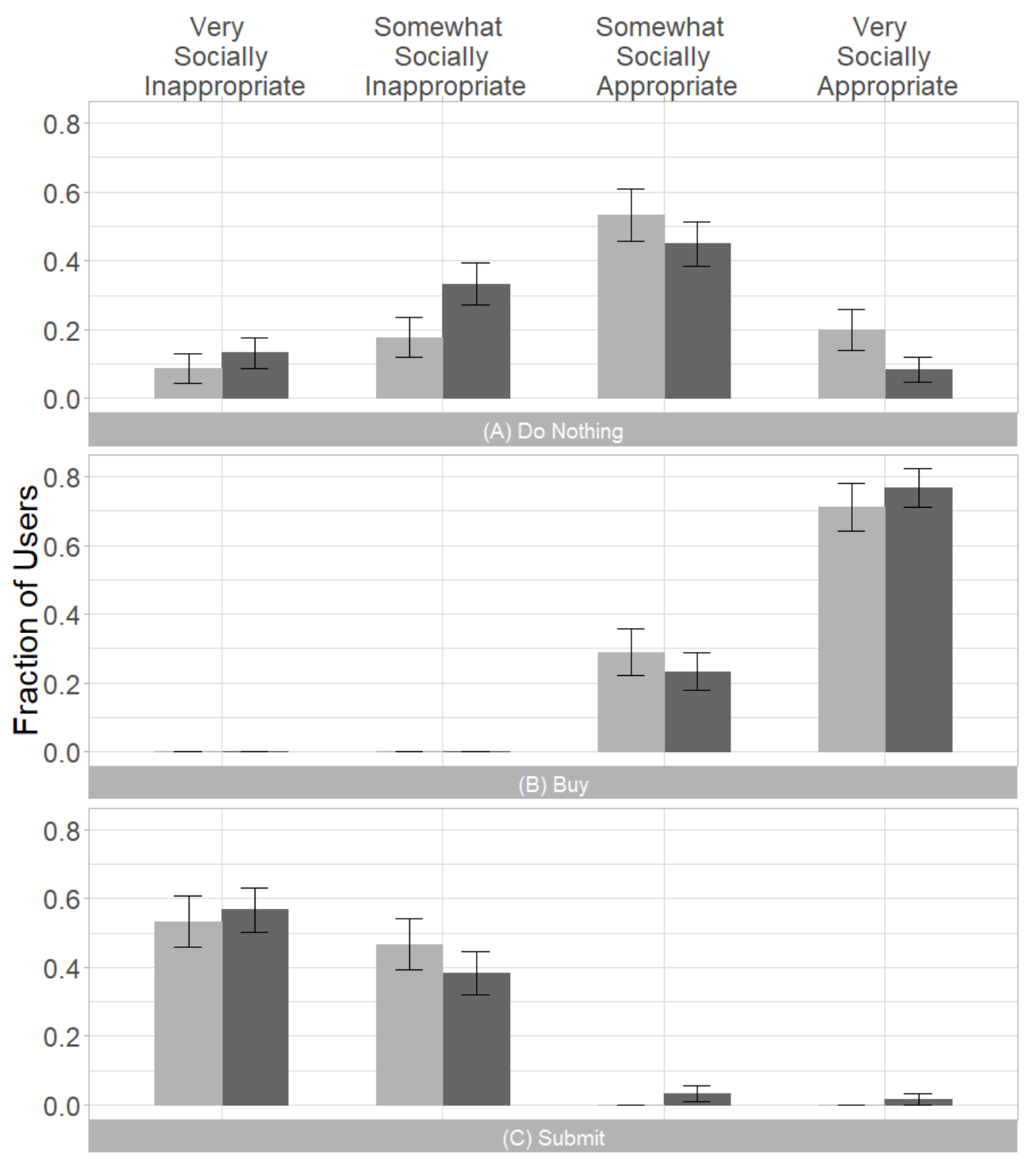

Figure A.4: Social Norms in the Rival and Non-rival Treatments

We measure participants' beliefs about how appropriate others view all three actions of the user (from 1 "very socially inappropriate" to 4 "somewhat socially appropriate"). The figure presents results for the rival and non-rival treatments. Given that we ask participants to judge the scenario where the user did not find the long solution on his own, action $(C)$ Submit equals stealing. The error bars show standard errors. 


\section{Robustness Treatment $\square$ Non-rival Treatment}

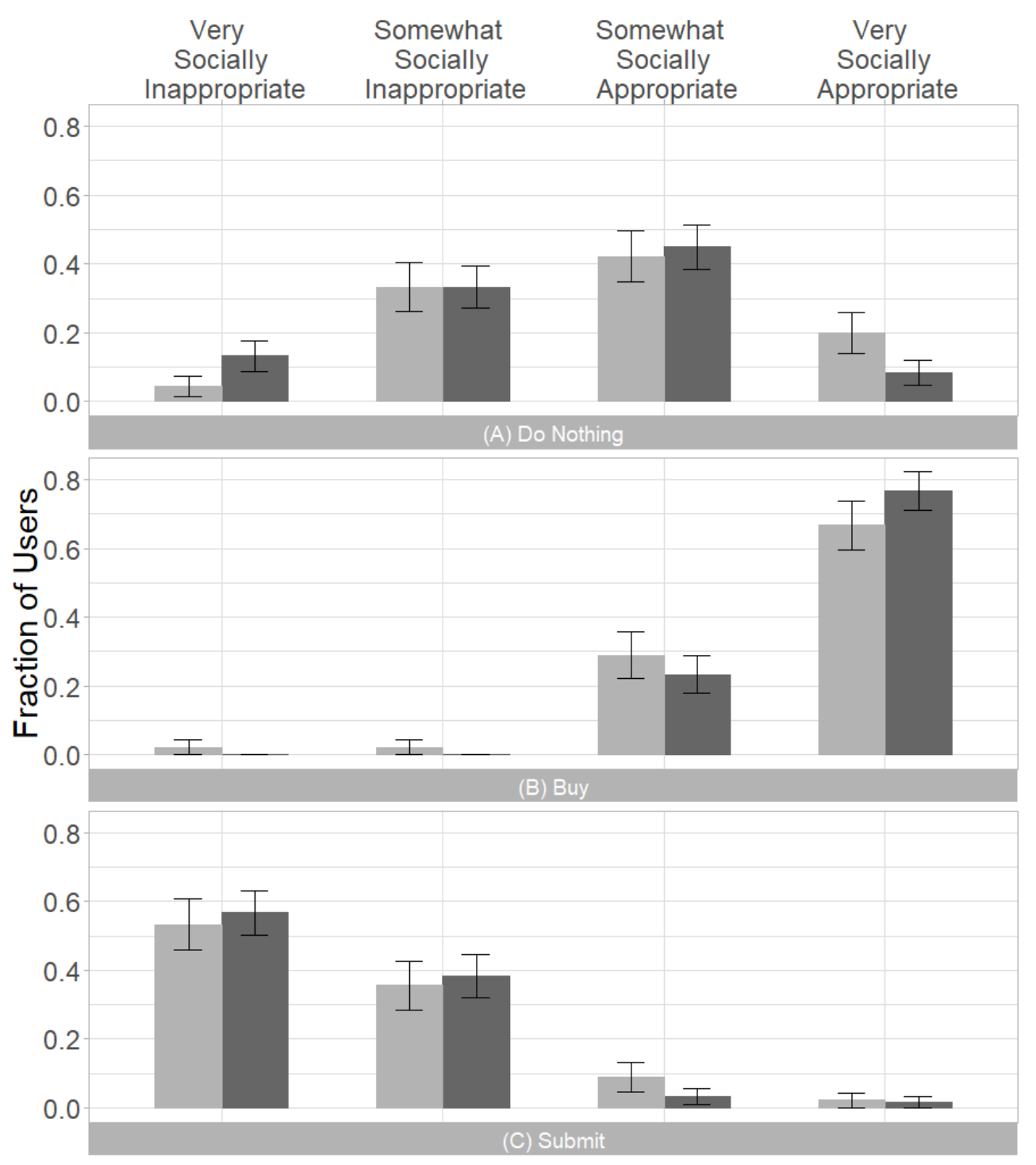

Figure A.5: Social Norms in the Robustness and Non-rival Treatments

We measure participants' beliefs about how appropriate others view all three actions of the user (from 1 "very socially inappropriate" to 4 "somewhat socially appropriate"). The figure presents results for the robustness and non-rival treatments. Given that we ask participants to judge the scenario where the user did not find the long solution on his own, action $(C)$ Submit equals stealing. The error bars show standard errors. 